41. 高橋酉藏, 岡田壽太郎, 刚米和夫：蛔虫駆除薬の研究 (第 2 報)

カイニン酸誘導体の合成 その 2

Torizo Takahashi, Jutaro Okada, and Kazuo Kariyone: Studies on

Insecticides. II. Synthesis of Kainic Acid Derivaties. (2).

(Pharmaceutical Institute, Medical Faculty, University of Kyoto, and Research Laboratory, Fujisawa Pharmacentical Industries, Ltd.)

By the application of amines, alcohols, and water to $\mathrm{N}$-acylkainic anhydrides (III, IV) and N-acyldihydrokainic anhydrides (VI, VII), obtained from $\alpha$-kainic acid ( I) and $\alpha$-dihydrokainic acid (II), the corresponding monoamides, monoesters, and $\mathrm{N}$ acylkainic acids (VIII to XXXIII) were prepared. These mono-substituted compounds were proved to be $\alpha$-substituted derivatives from the measurement of $\mathrm{pK}^{\prime}$ of $\mathrm{N}$-acetylglycine- and N-acylkainic derivatives. Further, (V) and (VIII) were derived to (XXXIV) and (XXXV) through N-acylkainic dichlorides.

(Received November 22, 1956)

前報1) に於いて著者等は蝐虫駆除作用を目的とする $\boldsymbol{\alpha}$-カイニン酸誘導体の合成について報告した。本報に於い ては $\beta$-カイニン酸誘導体の合成について報告する， $\beta$-カイニン酸は所謂 $\alpha$-カイ二ン酸の立体晎性体の一つとし て， $\mathrm{D}_{\mathcal{s}}$-ribo-2-carboxy-4-isopropeny1-3-pyrrolidineacetic acid (以下本報に於いてはカイニン酸と称す)なる

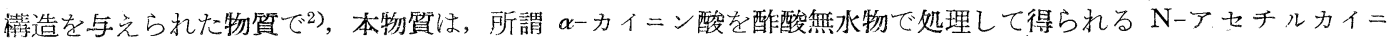
ン酸無水物を加水分解後脱アセチルして得られる3)。カイニン酸誘導体の蜔虫駆除作用については二, 三の報交が あるが4)，著者等は更に広範囲のカイニン酸誘導体の蜔虫駆除作用を検討する目的で，カイニン酸の N-acyl 置 換並びに $\mathrm{N}$ の $\boldsymbol{\alpha}$ 位または $\boldsymbol{\alpha}, \gamma$ 位にある carboxyl 基を ester, 及び amide に変化して 30 余の新誘導体を 合成した.

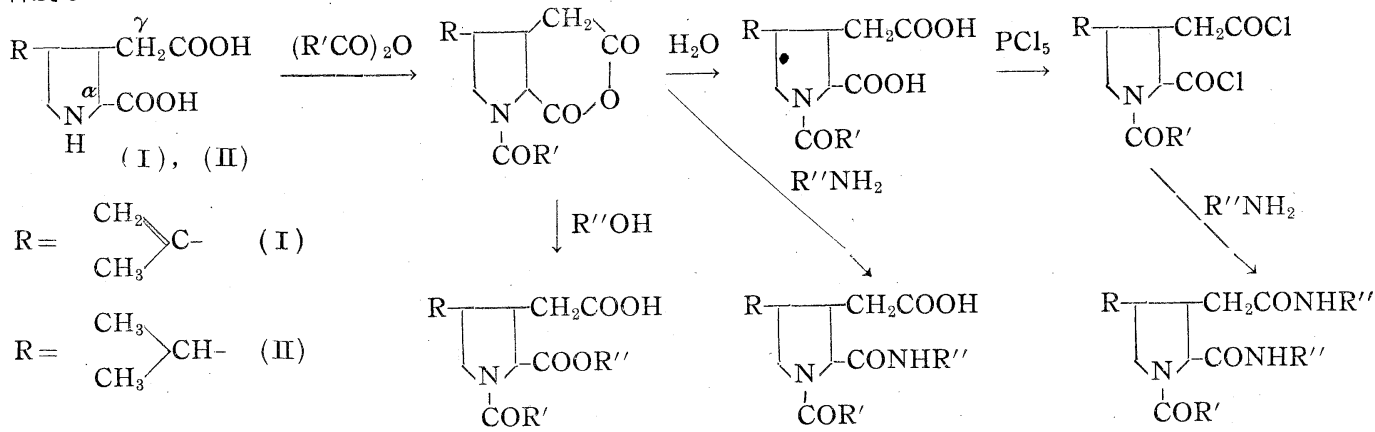

$\alpha$-カイニン酸 $(\mathrm{I})$ 或いは $\boldsymbol{\alpha}$-ジヒドロカイニン酸 (II) を酸無水物と処理して得た N-acylkainic anhydride $\left.{ }^{5}\right)$ (III), (VI), 或いは N-acyldihydrokainic anhydride5) (IV)，(VII) に水,アルコール類またはアミン類を作用させ て目的とする $\mathrm{N}$-acylkainic acid ${ }^{6,7)}$ その $\alpha$-monoester, $\alpha$-monoamide 及び $\mathrm{N}$-acyldihydrokainic acid $\alpha$ monoamide $(\mathrm{VII}) \sim(\mathrm{XXXIII)}$ を得た.

これらの反応の中アルコール類, アミン類で処理する際に起る N-acylkainic anhydride (III, VI) または N-

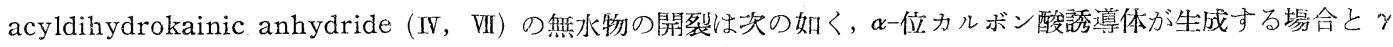

1) 高橋他：本誌 77, 178(1957).

2) 森体：本誌 $76,294(1956)$.

3) 获本：本誌 75,903(1955).

4) 村上他：本誌 73，1055(1955)；田村他：本誌 74, 454(1954); 田村：本誌 74, 1291(1954); 竹本他：本 誌 74, $107(1954)$; 羽野他：日薬理誌 50, $150 \S(1954)$; 田村：日寄生虫誌 3, 88 (1954)； 4, 152 (1955); 竹本他：日奇生出誌 $3,123(1954)$; 高村他：日寄生出誌 4, 213(1955).

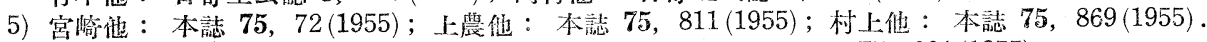

6) 宮崎：本誌 $75,692(1955)$. 7 ) 森本：本誌 $75,901(1955)$ 。 
位カルボン酸誘導体が生成する場合と二樣に考光られるが，後記の奏験事実より $\boldsymbol{a}$ 位の carboxy1 基が置換さ れると推定した。
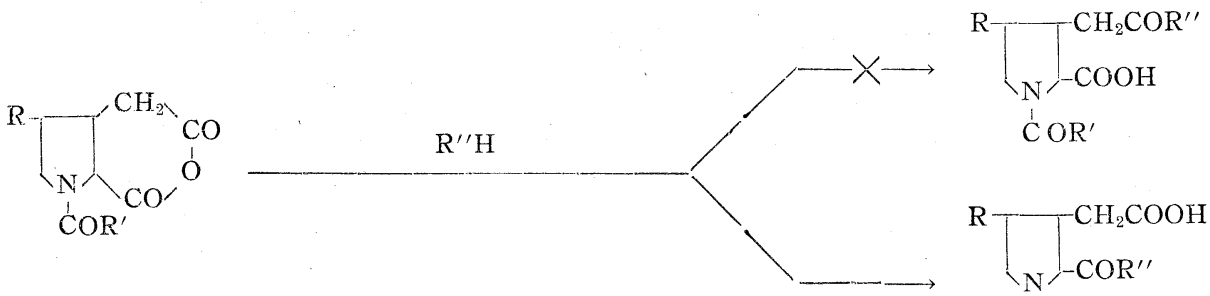

$\mathrm{COR}^{\prime}$

即台 N-acetylglycine と数種の N-acylkainic acid の誘導体を希メタノールに溶解し，それ等の $\mathrm{pK}^{\prime}$ を測 定した処，Table I 飞示特如き結果を得たので，上記の酸無水物の開裂に体つて得た誘導体は $\alpha$-カルボン酸誘導 体であると推定した。

Table I. $\mathrm{pK}^{\prime}$ in dil $\mathrm{MeOH}$

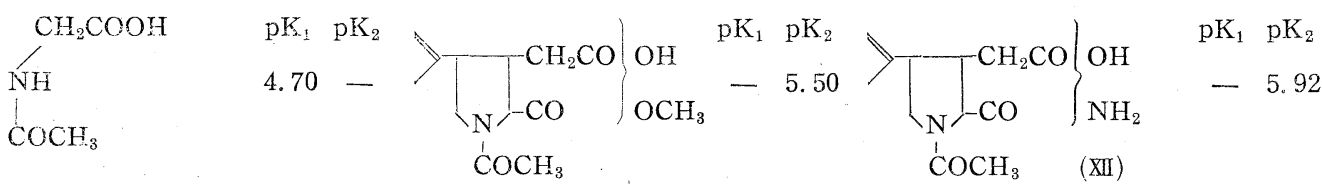<smiles>C=C1CN(C(C)=O)C(C(=O)O)C1CC(=O)O</smiles><smiles>C=C1CN(C(=O)OCC)C(CC(=O)O)C1(C)C</smiles>

(VIII)
4.506 .00<smiles>C=C1CN=CC1CC(=O)OCC</smiles>

(IX)<smiles>C=C1CN(C(=O)OC)C(=O)C1CC(=O)OC(O)CNc1ccccc1</smiles>

(XIII) 4.806 .20<smiles>C=C1C(CC(=O)OC)C2C(=S)C1(CC(=O)O)CN2C(=O)OCC</smiles>

(X)<smiles>C=C1CN(C(=O)OCC)C(CC(=O)C(O)(O)NCC)C1=C</smiles>

次に N-acylkainic acid ( $\mathrm{V}$, 䜣) に無水クロロホルム中五塩化燐を作用させて, N-acylkainic acid dichloride そ変化させ，アニリンと㤎理して N-acylkainic acid dianilide (XXXIV, XXXV) を得た。

なおこれ等のカインン酸謤導体の蜔虫駆除作用に関する薬理学的研究の結果は続報に於いて発表する予定で あ京。

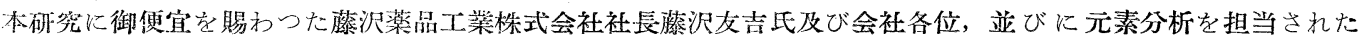
宗大䒕䒺分析センターの方々に深謝する。

\section{実 験 の 部}

N-Propionylkainic (or dihydrokainic) anhydride (VI, VII) $\boldsymbol{\alpha}$-kainic acid (I), 或いは $\boldsymbol{\alpha}$-dihydrokainic acid $(I I)$ に無永プロピオン陵の大過梨を加え, $130^{\circ}$ に 3 時閒加温後減压漲縮し，析出する結晶を沪取， $2 \mathrm{cc}$ の無水ベンゼンで洗浄後無水酢酸より再結晶. 結果を Table II に示す.

N-Propionylkainic acid (VIII) (V) $0.5 \mathrm{~g}$ を $5 \mathrm{cc}$ の熱蒸留水に溶解後減圧濃縮, 残留物を水より再結 晶. 得量 $0.4 \mathrm{~g}$. 白色針状晶, $\mathrm{mp} 172^{\circ} . \mathrm{C}_{13} \mathrm{H}_{19} \mathrm{O}_{5} \mathrm{~N}$ 計算值 C $57.99, \mathrm{H} 7.06, \mathrm{~N} 5.20$, 実験值 C 58.13, H 7.20, N 5.48 .

$\alpha$-Monomethyl(or ethy $\left.{ }_{1}^{1}\right) \mathrm{N}$-acetyl(or propionyl)kainate $[1$-Acetyl(or piperonyl)-2-methoxycarbonyl (or ethoxycarbonyl)-4-isopropenyl-3-pyrolidineacetic acid] (IX $\sim$ XI)

(VI) 或いは N-acetylkainic anhydriảe (III) に過剩のアルュール類を加えて加温し，舆水物の溶解後更に 15 分閒加温，次いで減圧濃縮，残 留物を再結晶. 結果を Table III に示す.

N-Acetylkainic acid $\alpha$-monoamide(1-Acetyl-2-carbamoyl-4-isopenyl-3-pyrrolidineacetic acid) (XII) (III) $0.5 \mathrm{~g}$ を液安約 $3 \mathrm{cc}$ に加光，ゆるく筧挥すると一旦溶解後固化する。これを一夜放置後少量の水に溶解 3 回減王濃縮を繰返し, 谈 $5 \mathrm{cc}$ の水溶解し, 計算量の 1.5 倍量の Amberlite IRA 50 を通過せ乙ぬ, 減圧濃縮 


\begin{tabular}{|c|c|c|c|c|c|c|}
\hline 필 & $z_{i} \quad \begin{array}{l}\overrightarrow{0} \\
10\end{array}$ & $\begin{array}{l}\infty \\
\infty \\
\text { iे }\end{array}$ & 還 & & $\begin{array}{l}\infty \\
\infty \\
+\end{array}$ & 4 \\
\hline 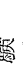 & 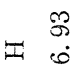 & 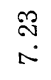 & 盤 & I & ๗ే & 8 \\
\hline & & $\begin{array}{l}\vec{F} \\
\vec{b}\end{array}$ & 虾 & 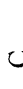 & $\begin{array}{l}\text { Oे } \\
\text { : }\end{array}$ & $\dot{b}$ \\
\hline & 乙 & $\begin{array}{l}\text { m. } \\
\text { is }\end{array}$ & 遇 & 2 & $\vec{\sigma}+\vec{f}$ & ii \\
\hline & 工 & $\stackrel{\text { \& }}{\sim}$ & 逜 & $I$ & $\stackrel{\text { 今 }}{\stackrel{\mathrm{N}}{\circ}}$ & (t) \\
\hline & 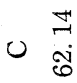 & $\begin{array}{l}8 \\
\dot{8} \\
\dot{0}\end{array}$ & 蓝 & $u$ & $\begin{array}{l}\text { 吕 } \\
\text { 今. }\end{array}$ & \\
\hline
\end{tabular}

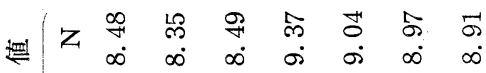

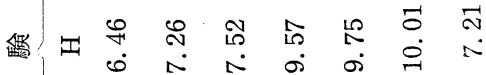

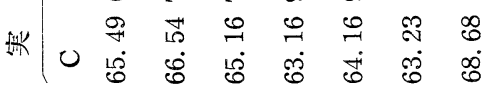

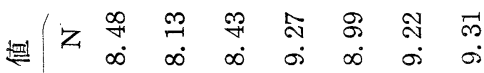

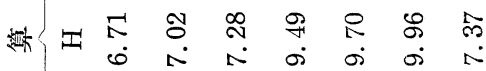

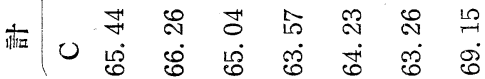

और 0 ช่

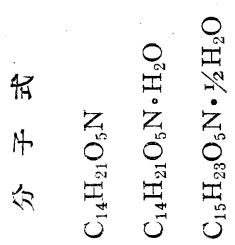

诲

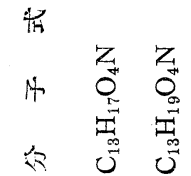

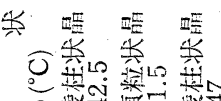

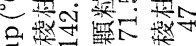

द्व

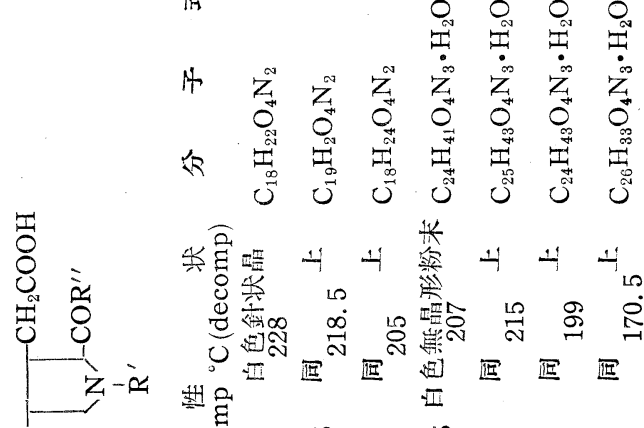

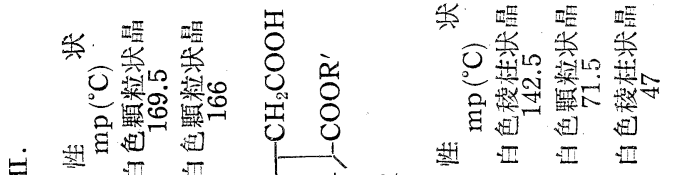

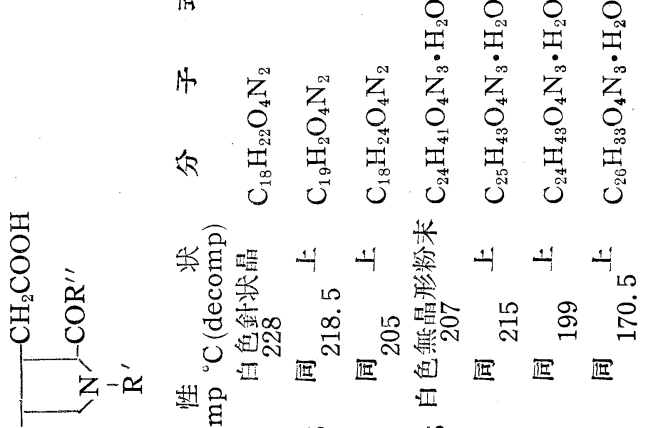

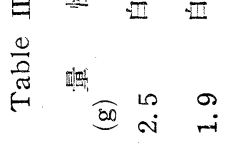

㠿

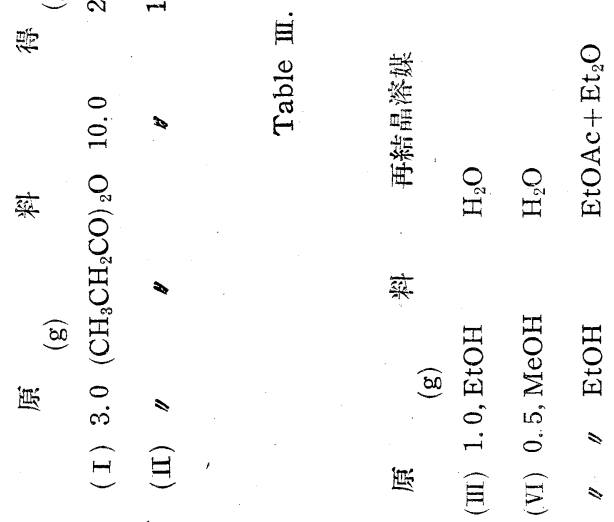

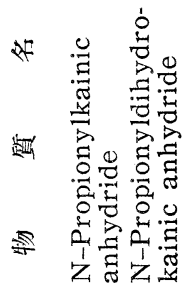

따

E

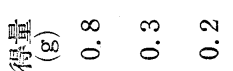

应

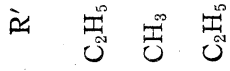

$\approx \quad \begin{gathered}\text { 壳 } \\ 0 \\ 0\end{gathered}$

政 氚

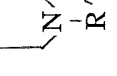

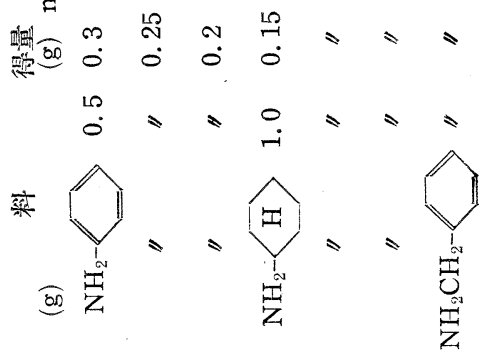

遛

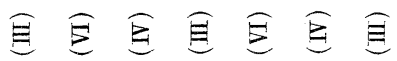

¿े

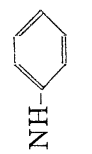

(1)

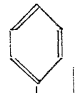

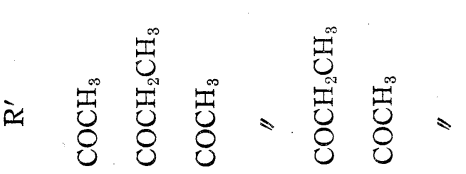

«

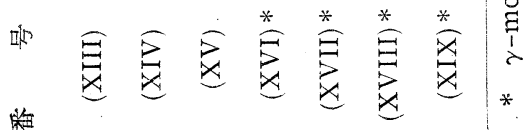




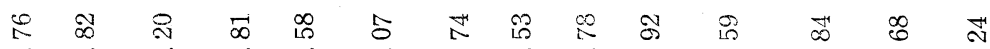

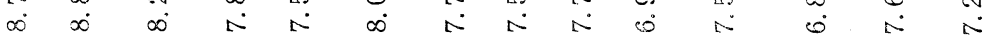

ก \&

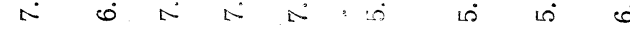

(1) F

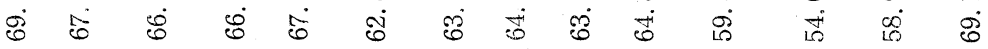

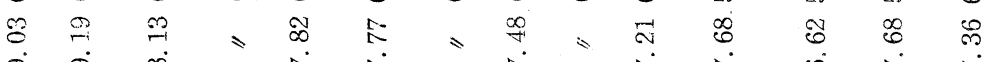

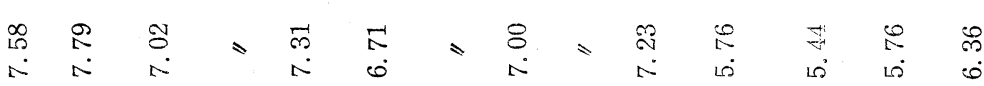

แี จ

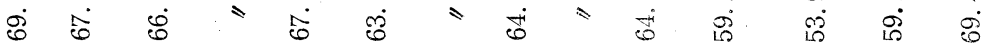

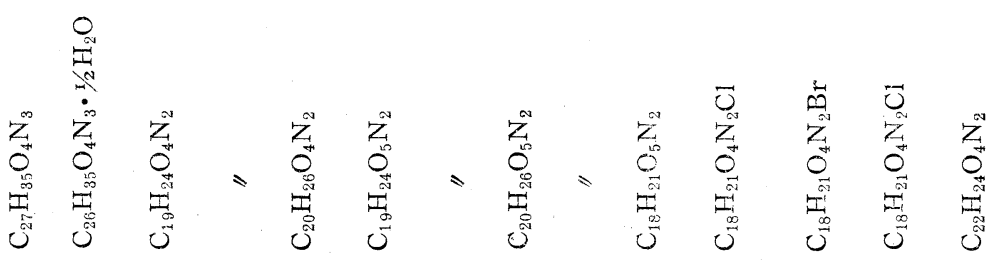

4 4

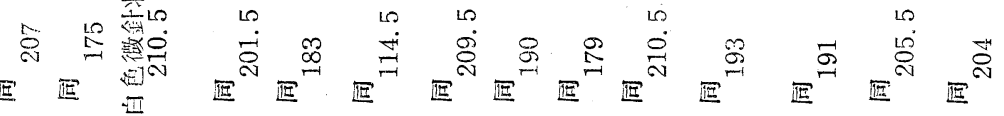

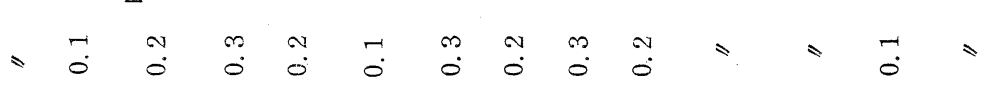

$==0^{\infty}=$
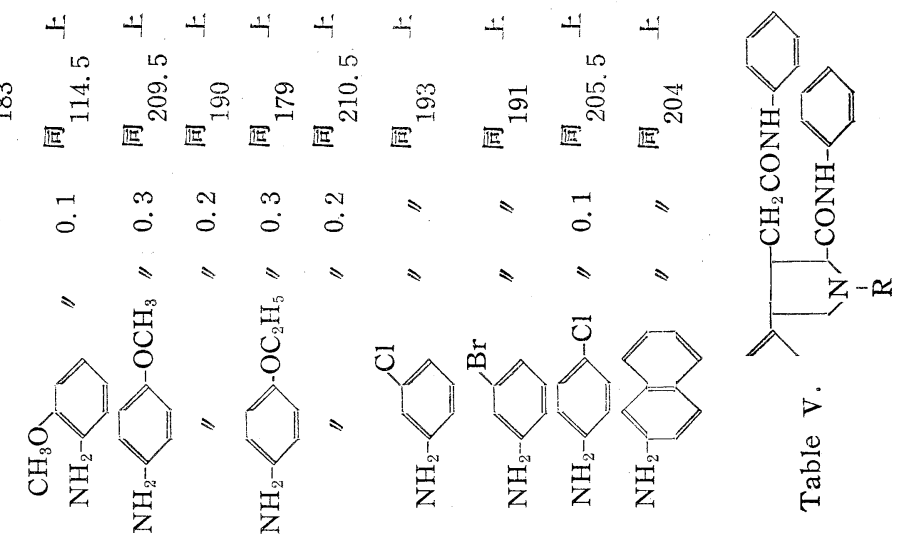

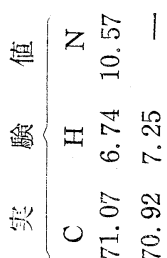

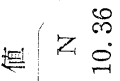

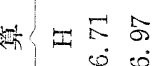

荘

th $\quad z_{1}^{\infty} z^{\infty}$

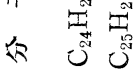

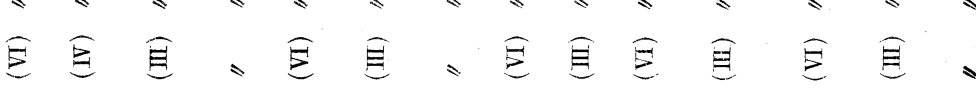

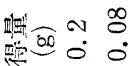

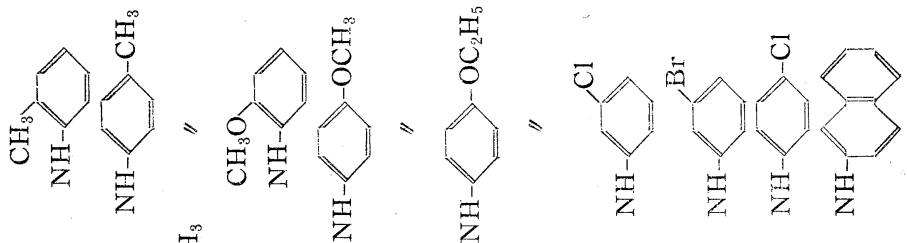

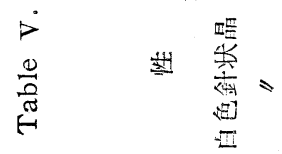

을

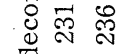

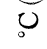

द्व

畨 10.

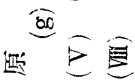

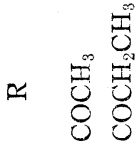

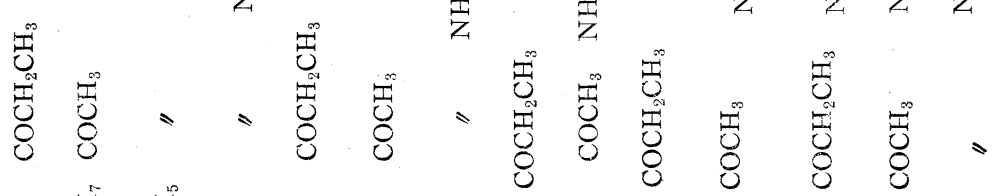

地蛋密

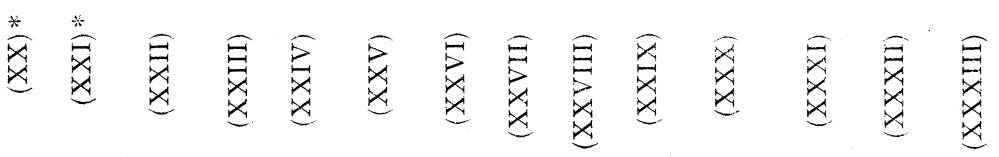


し水より再結晶. 得量 $0.3 \mathrm{~g}$. 白色細立方晶, $\mathrm{mp} 207^{\circ}$ (decomp) $\mathrm{C}_{12} \mathrm{H}_{18} \mathrm{O}_{4} \mathrm{~N}_{2}$ 計算值 $\mathrm{C} 56.68, \mathrm{H}$ 7.14, N 11.02, 实験值 C 56.35, H 7.40, N 10.99 .

N-Acetyl(or Propionyl)kainic(or dihydrokainic) acid $\alpha$-monoamide [1-Acetyl(or Propionyl)-2-carbamoyl-4-isopropenyl(or isopropyl)-3-pyrrolidineacetic acid) 及び N-Acetyl(or Propionyl)kainic(or dihydrokainic) acid $\alpha$-amide $\gamma$-ammonium salt (Ammomium 1-acetyl(or propionyl)-2-carbamoyl-4-isopropenyl (or isopropyl)-3-pyrrolidineacetate] (XIII〜XXXIII) $\quad$ (III)，(VI) 或いは N-acetyldihydrokainic anhydride (IV) にアミン類の過剩を加兄，130 150 K 20〜60 分閒加熱，原料無水物が溶解後放冷，可及的少 量のメタノールに溶解しやや多量の脱色炭末を加えて处理後，メタノールの 15２0 倍量のエーテルを加え氷室 汇放置，析出する球状の集針晶をメタノール・エーテルより再結晶. 結果を Table IV に示す.

N-Acetyl(or Propionyl)kainic acid dianilide (XXXIV, XXXV) N-acetylkainic acid (V)または

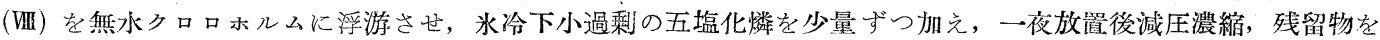
䒀水ベンゼン 5 cc ずっ 5 回抽出し, 粗 N-acetyl (or propionyl) kainic acid dichoride 溶液とし, これを冷却 下, 小過剩のアニリンを注意して滴下一夜放置. 希塩酸にて処理, 水洗, 脱水艺硝で乾燥後減圧濃縮. 残留する 战詷性物質をメタノール・エーテルより再結晶. 結果を Table V に示す.

京都大学医学部薬学科 攃沢薬品工業株式会社大除研究所

42. 富松祥郎：含空素共䡉系ジェンに関するDiels-Alder 反応（第 2 報*)

1-Cyclohexeny1-3, 4-dihydro-6,7-dimethoxyisoquinoline と無水マレイン酸の反応

Yoshio Tomimatsu : Diels-Alder Reaction of Diene Systems containing Nitrogen. II. Reaction of 1-Cyclohexeny1-3, 4-dihydro-6, 7-dimethoxyisoquinoline with Maleic Anhydride.

\title{
(Meiji College of Pharmacy**)
}

\begin{abstract}
Following the previous report on the reaction of 1-styry1-3,4-dihydroisoquinoline derivatives, as diene component of a $\mathrm{C}=\mathrm{C}-\mathrm{C}=\mathrm{N}$ system, with maleic anhydride, a reaction of 1-cyclohexenyl-3,4-dihydro-6,7-dimethoxyisoquinoline, possessing a cyclohexenyl group in place of styryi, with maleic anhydride was carried out under practically identical conditions. A compound (IV), identical in analytical values with that anticipated, was isolated as its picrate. In order to establish its structure, Hofmann degradation of the methiodide of the substance obtained by reduction and saponification of (IV), was carried out. Repeated three degradations resulted in the liberation of trimethylamine to form a neutral substance. Such a fact confirms the benzoquinolizine structure of the product and thereby indicates that this is a regular reaction. It was concluded from the result of the present and the preceding experiments that the diene component of $\mathrm{C}=\mathrm{C}-\mathrm{C}=\mathrm{N}$ system including the $\mathrm{C}=\mathrm{N}$ bond in $1-2$ positions of the 3,4-dihydroisoquinoline compound can take part in the DielsAlder type reaction.
\end{abstract}

(Received December 3, 1956)

著者は前報で $\mathrm{C}=\mathrm{C}-\mathrm{C}=\mathrm{N}$ 系の diene component として 3,4-dihydro-1-styrylisoquinoline 誘導体をとりこ れと無水マレイン酸の反応について報告したが今回はとの styryl の代りに cyclohexenyl 基を有する標記化合物 (III) と無水マレイン酸の反応を試みほぼ同樣の結果を得た。原料 (III) は Darzens') の方法に彷いcyclohexanoneより下式の如くして製した.

1-cyclohexenecarboxylic acid (I) chloride K変え 3,4-dimethoxyphenethylamine と SchottenEaumann 法で結合して amide体 (II) (mp 71〜 720）としこれを閉環して（III）を好収量で得，ピクラート[mp

* 第 1 報：本誌 $77,7(1957)$.

** Tanashi-machi, Kitatama-gun, Tokyo.

1) Darzens : Compt. rend. 144, $330(1907)$ 